\title{
Estimates of success in patients with sciatica due to lumbar disc herniation depend upon outcome measure
}

\author{
Anne Julsrud Haugen · Lars Grøvle • \\ Jens Ivar Brox • Bård Natvig • Anne Keller • \\ Dag Soldal $\cdot$ Margreth Grotle
}

Received: 26 October 2010/Revised: 9 February 2011/Accepted: 12 April 2011/Published online: 24 April 2011

(C) The Author(s) 2011. This article is published with open access at Springerlink.com

\begin{abstract}
The objectives were to estimate the cut-off points for success on different sciatica outcome measures and to determine the success rate after an episode of sciatica by using these cut-offs. A 12-month multicenter observational study was conducted on 466 patients with sciatica and lumbar disc herniation. The cut-off values were estimated by ROC curve analyses using Completely recovered or Much better on a 7-point global change scale as external criterion for success. The cut-off values
\end{abstract}

A. J. Haugen $(\bowtie) \cdot$ L. Grøvle

Department of Rheumatology, Østfold Hospital Trust,

1603 Fredrikstad, Norway

e-mail: annhau@so-hf.no

J. I. Brox

Section for Back Surgery and Physical Medicine and

Rehabilitation, Orthopaedic Department,

Oslo University Hospital, Rikshospitalet, Oslo, Norway

B. Natvig · M. Grotle

National Resource Centre for Rehabilitation in Rheumatology,

Diakonhjemmet Hospital, Oslo, Norway

\section{A. Keller}

Department of Physical Medicine and Rehabilitation,

Oslo University Hospital, Ullevaal, Oslo, Norway

D. Soldal

Department of Rheumatology, Sørlandet Hospital Health

Enterprise, Kristiansand, Norway

M. Grotle

FORMI (Communication Unit for Musculoskeletal Disorders), Oslo University Hospital, Ullevaal, Oslo, Norway

B. Natvig

Department of General Practice and Community Medicine,

ASAM, University of Oslo, Oslo, Norway (references in brackets) at 12 months were leg pain VAS 17.5 (0-100), back pain VAS $22.5(0-100)$, Sciatica Bothersomeness Index 6.5 (0-24), Maine-Seattle Back Questionnaire 4.5 (0-12), and the SF-36 subscales bodily pain 51.5, and physical functioning $81.7(0-100$, higher values indicate better health). In conclusion, the success rates at 12 months varied from 49 to $58 \%$ depending on the measure used. The proposed cut-offs may facilitate the comparison of success rates across studies.

Keywords Sciatica - Outcome measures - Pain · Disability

\section{Introduction}

Sciatica, defined as nerve root pain-or radicular pain in the leg below the knee, is most commonly caused by lumbar disc herniation. The natural course of sciatica is often described as favourable, and it is presumed that the symptoms of the majority of patients improve [11, 18, 22]. A recent 1-year follow-up study of patients with sciatica randomised to early surgery or to prolonged conservative treatment found recovery rates of $95 \%$ for both groups [17]. On the other hand, in the SPORT study, only $44.7 \%$ of the patients who did not undergo surgery and $77.1 \%$ of the surgically treated patients were satisfied with their symptoms after 1 year [23]. These divergent results on sciatica patients are challenging [4], and the different outcomes available make it difficult to compare the results of published studies. Primary patient-reported outcomes commonly used in clinical studies on sciatica are patientrated global change [1, 8, 14, 17, 23], leg pain [15, 17, 22], back pain [22], Medical Outcomes Study Short Form 36 (SF-36) bodily pain and physical functioning [23], North 
American Spine Society (NASS) neurogenic symptoms score (NSS) [20], Oswestry Disability Index (ODI) [23] and the Roland Morris disability questionnaire (RMDQ) $[17,22]$. Few studies have used sciatica-specific outcomes such as the Sciatica Bothersomeness and Frequency Indices, and then only as secondary outcomes $[1,17,23]$.

Clinical findings and imaging have shown little relevance for change of symptoms in patients with sciatica. Therefore, patient's self-reports are important. The minimum clinically important difference (MCID) represents the smallest improvement or change in score based on an external anchoring question about the patient's percieved improvement $[5,13]$. However, although there is a large improvement on a measure, the patient might not have had a good outcome or success. A cut-off differing between success and non-success makes it possible to estimate the rate of patients with a good outcome. As long as no consensus exists on the definition of success, there is no agreement on the cut-off values for success for various outcome measures of sciatica. A 7-point Likert scale has been used as a recovery scale (complete or nearly complete disappearance of sciatica symptoms) [17] and as a global perceived effect scale (completely recovered and much improved) [12] in patients with sciatica.

The aims of this study were to estimate the cut-off points for success on different outcome measures and to determine the success rate after an episode of sciatica using the outcome cut-off values.

\section{Materials and methods}

\section{Design}

We conducted a prospective multicentre observational study of patients with sciatica. The sample size was calculated based on an expectation that surgical treatment would be necessary for $30 \%$ of the patients and that $70 \%$ of those who were surgically treated and $50 \%$ of those who were not surgically treated would experience a good outcome [1]. Power analysis indicated a sample size on 300 patients requiring $90 \%$ power with a two-sided exact Fisher test of 5\% significance level. Taking loss-to-follow-up into consideration we ended up with a study sample of 400 patients. The study protocol was approved by the Regional Committee for Medical Research Ethics and The Ombudsmann for Privacy in Research at the Norwegian Social Science Data Services.

\section{Patients}

Patients were recruited from specialty back clinics at four hospitals in southeast Norway (Sykehuset Østfold,
Sørlandet Sykehus, Oslo Universitetssykehus Ullevål and Sykehuset Innlandet). Patients were referred to the specialty back clinics from the primary health care service. Assessment and treatment were conducted as usual in the back clinics. A physician or physiotherapist informed consecutive eligible patients about the study. Inclusion criteria were age $\geq 18$ years and radiating pain below the knee level, and/or paresis and a disc herniation at the corresponding level and side according to magnetic resonance imaging (MRI) or computed tomography (CT). Exclusion criteria were prior surgery at the same disc level, fracture, infection, malignancy, pregnancy, and lack of fluency in Norwegian. All patients signed an informed consent form after receiving oral and written information.

\section{Procedure}

At the first visit, a questionnaire on sociodemographic factors (age, gender, education length, smoking status and work status) was completed. Patients also reported their history of previous sciatica and the duration of relevant sciatica episodes. A clinical examination was carried out by trained physiotherapists or physicians at the departments of rheumatology, physical medicine and rehabilitation, or orthopaedics.

The assessment included motor function of the muscles of the knee, leg and toe, the Trendelenburg test, sensory loss in the leg, reflexes of the Achilles tendon and patella (all deemed abnormal if reduced) and the straight leg raising test (deemed abnormal if $<60^{\circ}$ ). Number of tenderpoints were recorded. Standardisation of testing procedures was done in meetings with the participating centres.

A follow-up questionnaire and a prepaid envelope were sent to the patients after 3,6 and 12 months. The date was recorded for patients who underwent back surgery. A study nurse sent a reminder after 2 weeks if no reply was obtained.

\section{Measures}

Leg pain and low back pain were measured using the visual analogue scale (VAS) 0-100. The Sciatica Bothersomeness Index (SBI), which is a composite score of four questions (each score ranging from 0-6) that include elements of leg pain and sensory and motor disturbances, was used [7, 16]. Total score ranges from 0 to 24 and higher scores indicate worse symptoms. The Maine-Seattle Back Questionnaire (MSBQ) $[2,7]$ which was developed from the RMDQ and modified for sciatica patients, was used to measure functional status. The scale is composed of 12 items and the score ranges from 0 to 12 , higher scores indicating greater disability. The MSBQ mainly assesses disability, but also includes questions about pain. The Norwegian versions of 
the SBI and the MSBQ were recently validated [7]. The bodily pain and physical functioning subscales of SF-36 [21] are parts of a generic quality of life questionnaire in widespread use, including studies on sciatica [1, 23, 24]. Scores range from 0 to 100 and higher values indicate better health.

The follow-up questionnaires included a 7-item global change scale for leg and back pain with the following categories: Completely recovered, Much better, Better, A little better, No change, A little worse and Much worse. Patients were categorised as success if they responded with Completely recovered or Much better. Satisfaction to spend the rest of life in the current state was registered using a 5-item Likert scale with the wording Very satisfied, A little satisfied, Neither satisfied nor not, A little dissatisfied, and Very Dissatisfied.

\section{Statistical analyses}

Baseline and follow-up comparisons between groups were analysed using an independent $t$-test for continuous data and $\chi^{2}$ for categorical data. Floor or ceiling effects were defined as $>15 \%$ of scores in the lowest or highest parts of the scales, respectively [19].

A receiver operating characteristic (ROC) curve was obtained by plotting every possible cut-off score's sensitivity on the $y$-axis against 1 -specificity on the $x$-axis. Sensitivity was defined as the proportion of patients who were correctly classified in the success group (Completely recovered or Much better). Specificity was defined as the proportion of patients who were correctly classified in the non-success group. The value on the curve closest to the upper left corner shows the highest sensitivity and specificity and was considered the best cut-off score for distinguishing between success and non-success. The area under the ROC curve (AUC) reflects the scoring system's ability in differentiating between success and non-success. An AUC value $>0.70$ was considered satisfactory [19].

McNemar's test was used when comparing sensitivity of two diagnostic measures where the cut-off point was set to specificity $80 \%$ for each measure.

The Statistical Package for Social Sciences Version 17.0 (SPSS Inc., Chicago, IL) was used for data analysis.

\section{Results}

Four hundred sixty-six patients were included in the study; $268(57.5 \%)$ were men. The mean age was $43.6 \pm 11.5$ years. Patient characteristics are presented in Table 1. Fifty-seven $(12.2 \%)$ patients, six of whom underwent surgery, were lost to follow-up at 1 year. At baseline these patients were significantly younger, had a higher leg pain score and more often tested positive on the straight leg raising test than patients who completed the study (Table 1).

Patients were classified as acute if duration of current sciatica episode was less than 3 months and chronic if duration was 3 months and more. The acute patients ( $n=192,41.4 \%)$ represented more males, higher score on SBI, lower scores on SF-36 bodily pain and physical functioning, and higher frequency of reduced motor function, sensory loss and reflex depletion at the clinical examination. Baseline leg pain intensity score was $>90$ in 100 patients. The SF-36 bodily pain had a ceiling effect as $99(21.2 \%)$ patients reported a score of 0 (the worst degree of pain).

The 3-, 6- and 12-month questionnaires were answered by 434 (93.1\%), $423(90.8 \%)$ and $409(87.8 \%)$ patients, respectively. Mean leg pain score decreased from $63.2 \pm 28.2$ at baseline to $26.7 \pm 28.8$ at 12 months. Over the same period, the mean SBI score decreased from $14.2 \pm 5.0$ to $7.2 \pm 6.1$ and the MSBQ score decreased from $8.1 \pm 2.6$ to $4.2 \pm 3.4$. Those who worked full time were $93(20.0 \%)$ at baseline, $183(42.4 \%)$ at 3 months, 220 $(52.0 \%)$ at 6 months and $250(61.1 \%)$ at 12 months.

By the 12-month follow-up, 126 patients had received surgical treatment. Patients selected for surgery were younger, had more frequently positive straight leg raising test and reported significantly more pain and disability at baseline than those who did not undergo surgery. At 12 months, the surgically treated patients had significantly better outcomes in terms of leg pain $(P=0.001)$ and SBI $(P<0.001)$ than non-surgically treated patients, whereas outcomes such as back pain, MSBQ and SF-36 bodily pain and physical functioning scores did not differ between surgically and non-surgically treated patients (Fig. 1).

Table 2 presents the mean scores for the outcome variables at 12 months according to the global change scale. All outcome scores increased correspondingly with the categories in the global change scale, except the items No change, A little worse and Much worse for SBI and VAS in leg and back. Using the global change scale 222 (54.4\%) of the patients reported success; 83 were of the surgically treated group $(69.2 \%)$ and 139 were of the nonsurgically treated group (48.3\%). Overall, $188(46.1 \%)$ of the patients indicated they were satisfied to spend the rest of their lives in their current state; 72 were of the surgically treated group $(60.0 \%)$ and 116 were of the non-surgically treated group $(40.4 \%)$.

The ROC analyses showed a high AUC (0.76-0.89) for leg and back pain scores, SBI, MSBQ and the SF-36 bodily pain and physical functioning scores at 3,6 and 12 months. Similar results were observed using satisfied to spend the rest of life in the current state as an external criterion (AUC 0.74-0.87). Cut-off points with the highest sensitivity and 
Table 1 Baseline

characteristics for 409 patients with complete data and 57 non-responders at the 1-year follow-up

Data are presented as number (percentage) unless otherwise indicated

VAS Visual Analogue Scale, $S B I$ Sciatica Bothersomeness Index, $M S B Q$ Maine-Seattle Back Questionnaire, $S F-36$ Medical Outcomes Study Short-Form Health Survey

${ }^{a}$ Higher score indicates better health

\begin{tabular}{|c|c|c|c|}
\hline & $\begin{array}{l}\text { Total cohort } \\
n=409\end{array}$ & $\begin{array}{l}\text { Non-responders } \\
n=57\end{array}$ & $P$ \\
\hline Age years, mean (SD) & $44.2(11.4)$ & $39.2(10.9)$ & 0.002 \\
\hline Males & $232(56.7)$ & $36(63.2)$ & 0.357 \\
\hline Current smoker & $171(42.1)$ & $29(51.8)$ & 0.171 \\
\hline Education $>12$ years & 197 (49.6) & $30(53.6)$ & 0.580 \\
\hline Working status & & & 0.440 \\
\hline Working full time & $83(20.3)$ & $10(17.5)$ & \\
\hline Partly sick leave & $48(11.7)$ & $6(10.5)$ & \\
\hline Total sick leave & $200(48.9)$ & $27(47.4)$ & \\
\hline Rehabilitation, disability pension & $45(11.0)$ & $8(14.1)$ & \\
\hline Other & $33(8.1)$ & $6(10.4)$ & \\
\hline Previous disc surgery & $17(4.2)$ & $1(1.8)$ & 0.374 \\
\hline First sciatica episode & $183(44.9)$ & $27(48.2)$ & 0.636 \\
\hline Duration current sciatica episode & & & 0.586 \\
\hline$<3$ months & $172(42.3)$ & $20(35.1)$ & \\
\hline $3-6$ months & $135(33.2)$ & $21(36.8)$ & \\
\hline$>6$ months & $100(24.6)$ & $16(28.1)$ & \\
\hline VAS low back pain $(0-100)$, mean (SD) & $41.4(30.0)$ & $51.6(28.6)$ & 0.015 \\
\hline VAS leg pain $(0-100)$, mean (SD) & $62.6(28.1)$ & $68.0(28.1)$ & 0.180 \\
\hline SBI (0-24), mean (SD) & $14.2(5.0)$ & $14.5(5.2)$ & 0.740 \\
\hline MSBQ (0-12), mean (SD) & $8.1(2.6)$ & $8.8(2.5)$ & 0.050 \\
\hline SF-36 $\left(0-100^{\mathrm{a}}\right)$ bodily pain, mean (SD) & $22.9(17.7)$ & $21.2(17.4)$ & 0.480 \\
\hline SF-36 $\left(0-100^{\mathrm{a}}\right)$ physical functioning, mean (SD) & $50.4(25.4)$ & $45.4(25.7)$ & 0.172 \\
\hline \multicolumn{4}{|l|}{ Clinical examination } \\
\hline Straight leg raising $<60^{\circ}$ & $224(55.6)$ & $43(75.4)$ & 0.004 \\
\hline Sensory loss & $236(58.1)$ & $37(64.9)$ & 0.330 \\
\hline Muscle weakness & $177(44.1)$ & $26(47.3)$ & 0.661 \\
\hline Reflex weakness & $190(47.0)$ & $22(40.0)$ & 0.327 \\
\hline$>10$ tenderpoints & $34(8.9)$ & $5(9.4)$ & 0.894 \\
\hline
\end{tabular}

\section{Discussion}

The main finding of this sciatic cohort study was that the success rates among the different outcome measures at 1 year varied from 49 to $58 \%$. This indicates that success rates cannot be used for comparison between studies unless the success criterion is exactly defined.

We used a strict definition of success using Completely recovered or Much better as the success criterion. In the non-success group, there were patients with both deterioration and some improvement of the symptoms. After 1 year, $112(27.5 \%)$ patients reported their condition as Better or A little better, but only 14 (12.5\%) of them were satisfied with their symptoms.

The ROC cut-off was constructed using the 12-month absolute score for each variable and Completely recovered or Much better as the external criterion. When the same external criterion was used for the 12-month change scores, the results were similar (AUC 0.72-0.87). We decided to use cut-off values for the absolute follow-up scores in stead 

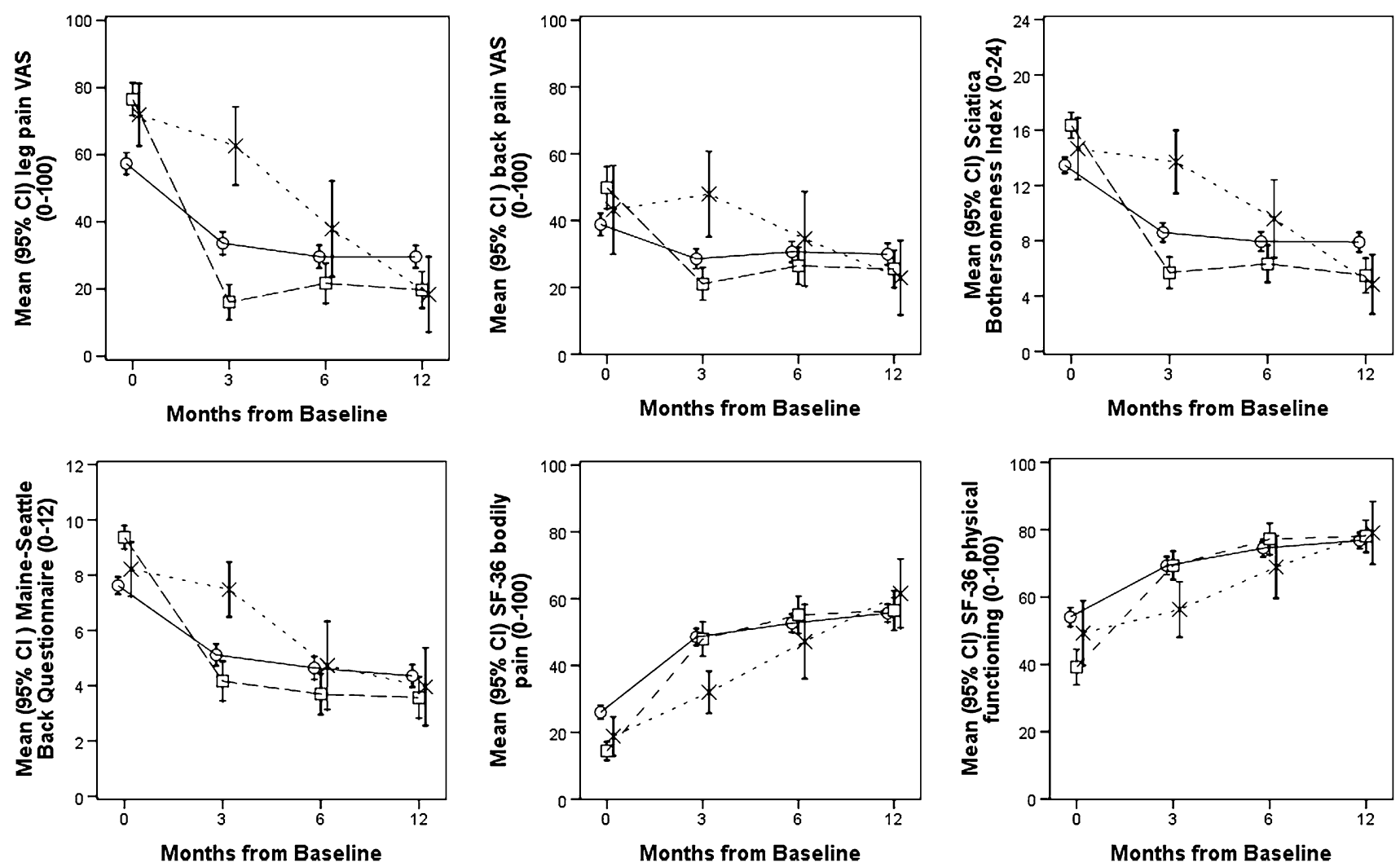

Fig. 1 Time course for scores for leg pain (VAS), back pain (VAS), Sciatica Bothersomeness Index, Maine-Seattle Back Questionnaire, CIs) in patients treated without surgery $(n=289)$ (circles), surgery within 3 months of registration $(n=98)$ (squares) and surgery SF-36 bodily pain and SF-36 physical functioning (means with $95 \%$ between 3 and 12 months of registration $(n=28)$ (multi symbols)

Table 2 Mean (SD) scores at 12 months for leg pain (VAS), back pain (VAS), Sciatica Bothersomeness Index (SBI), Maine-Seattle Back Questionnaire (MSBQ), SF-36 bodily pain, SF-36 physical functioning registered at every category of the 7-point global change scale

\begin{tabular}{|c|c|c|c|c|c|c|c|}
\hline $\begin{array}{l}\text { Global change of } \\
\text { sciatica symptoms }\end{array}$ & $n^{\mathrm{a}}$ & $\begin{array}{l}\text { Leg pain } \\
(0-100)\end{array}$ & $\begin{array}{l}\text { Back pain } \\
(0-100)\end{array}$ & $\begin{array}{l}\text { Sciatica } \\
\text { Bothersomeness } \\
\text { Index } \\
(0-24)\end{array}$ & $\begin{array}{l}\text { Maine-Seattle } \\
\text { Back Questionnaire } \\
(0-12)\end{array}$ & $\begin{array}{l}\text { SF-36 bodily } \\
\text { pain } \\
\left(0-100^{\mathrm{b}}\right)\end{array}$ & $\begin{array}{l}\text { SF-36 physical } \\
\text { functioning } \\
\left(0-100^{\mathrm{b}}\right)\end{array}$ \\
\hline Completely recovered & 61 & $1.9(6.0)$ & $6.3(18.1)$ & $0.9(2.0)$ & $0.7(1.5)$ & $80.6(22.9)$ & $92.4(11.3)$ \\
\hline Much better & 161 & $14.4(16.7)$ & $16.1(15.0)$ & $4.6(3.6)$ & $2.6(2.1)$ & $64.9(18.3)$ & $85.6(14.2)$ \\
\hline Better & 59 & $28.9(22.5)$ & $30.6(22.1)$ & $8.7(5.2)$ & $5.2(3.0)$ & $50.5(18.0)$ & $72.9(19.8)$ \\
\hline A little better & 53 & $40.0(27.6)$ & $49.8(25.9)$ & $10.3(4.3)$ & $6.5(3.0)$ & $41.3(16.8)$ & $65.2(22.1)$ \\
\hline No change & 44 & $62.9(27.3)$ & $55.3(28.3)$ & $14.6(5.1)$ & $7.7(2.2)$ & $36.5(19.0)$ & $60.8(20.3)$ \\
\hline A little worse & 20 & $52.5(28.3)$ & $61.0(21.4)$ & $13.3(5.3)$ & $8.2(1.7)$ & $29.7(18.3)$ & $59.4(22.1)$ \\
\hline Much worse & 10 & 82.1 (14.6) & $55.9(32.5)$ & $18.3(5.2)$ & $9.3(2.0)$ & $21.5(16.0)$ & $44.0(25.1)$ \\
\hline
\end{tabular}

a 408 completed the questionnaire

${ }^{b}$ Higher values indicate better health

of change scores in order to enhance feasibility. Cut-off values of follow-up scores can easily be used in clinical practice as a guideline for evaluating outcome of sciatica.

In the ROC-cut-off analyses all outcomes showed satisfactory ability to discriminate between success and nonsuccess. However, the scores for the MSBQ at 12 months had the highest AUCs and a significantly higher sensitivity when specificity was locked at $80 \%$ and might be the most preferable score in evaluating pain and function during sciatica. Over time, the SBI and the MSBQ showed the most stable cut-off points.

Patients selected for surgery had a higher baseline score and a more rapid decline in symptoms than those who did not undergo surgery. However, the outcomes at 1-year 
Table 3 Cut-off values with sensitivity and specificity using "Completely recovered or Much better" as external criterion

\begin{tabular}{|c|c|c|c|c|}
\hline & \multicolumn{2}{|c|}{3 months } & \multicolumn{2}{|c|}{12 months } \\
\hline & $\begin{array}{l}\text { Cut-off } \\
\text { value }\end{array}$ & $\begin{array}{l}\text { Sens, } \\
\text { spec }\end{array}$ & $\begin{array}{l}\text { Cut-off } \\
\text { value }\end{array}$ & $\begin{array}{l}\text { Sens, } \\
\text { spec }\end{array}$ \\
\hline \multicolumn{5}{|l|}{ VAS leg (0-100) } \\
\hline Total population & 20.5 & 78,79 & 17.5 & 78,77 \\
\hline Acute & 19.5 & 75,67 & 18.5 & 78,74 \\
\hline Chronic & 21.5 & 84,85 & 16.5 & 76,79 \\
\hline Surgery & 11.5 & 80,80 & 23.0 & 91,81 \\
\hline No surgery & 22.5 & 75,76 & 18.5 & 73,75 \\
\hline Male & 19.5 & 76,74 & 13.5 & 75,75 \\
\hline Female & 21.5 & 83,85 & 24.0 & 86,83 \\
\hline \multicolumn{5}{|l|}{ VAS back (0-100) } \\
\hline Total population & 19.5 & 71,72 & 22.5 & 79,78 \\
\hline Acute & 20.5 & 77,73 & 23.5 & 76,77 \\
\hline Chronic & 19.5 & 70,70 & 19.5 & 78,80 \\
\hline Surgery & 28.5 & 89,65 & 24.5 & 82,84 \\
\hline No surgery & 20.5 & 75,70 & 22.5 & 78,77 \\
\hline Male & 20.5 & 73,70 & 21.5 & 79,77 \\
\hline Female & 19.5 & 74,74 & 25.5 & 80,81 \\
\hline \multicolumn{5}{|c|}{ Sciatica Bothersomeness Index (0-24) } \\
\hline Total population & 6.5 & 77,81 & 6.5 & 78,75 \\
\hline Acute & 7.5 & 78,75 & 6.5 & 76,73 \\
\hline Chronic & 6.5 & 82,82 & 6.5 & 80,76 \\
\hline Surgery & 6.5 & 82,80 & 5.5 & 86,87 \\
\hline No surgery & 7.5 & 80,78 & 6.5 & 70,73 \\
\hline Male & 6.5 & 76,76 & 5.5 & 80,87 \\
\hline Female & 8.5 & 84,83 & 6.5 & 72,81 \\
\hline \multicolumn{5}{|c|}{ Maine-Seattle Back Questionnaire (0-12) } \\
\hline Total population & 4.5 & 74,81 & 4.5 & 86,78 \\
\hline Acute & 4.5 & 71,77 & 3.5 & 76,85 \\
\hline Chronic & 4.5 & 76,83 & 4.5 & 87,81 \\
\hline Surgery & 5.5 & 79,85 & 4.5 & 87,84 \\
\hline No surgery & 4.5 & 75,81 & 3.5 & 77,83 \\
\hline Male & 4.5 & 77,79 & 3.5 & 82,81 \\
\hline Female & 5.5 & 77,76 & 4.5 & 87,88 \\
\hline \multicolumn{5}{|c|}{ SF-36 bodily pain $(0-100)$} \\
\hline Total population & 41.5 & 71,72 & 51.5 & 74,80 \\
\hline Acute & 41.5 & 70,70 & 51.5 & 74,74 \\
\hline Chronic & 41.5 & 70,73 & 56.5 & 74,85 \\
\hline Surgery & 36.5 & 79,75 & 46.5 & 82,71 \\
\hline No surgery & 46.5 & 75,73 & 61.5 & 74,84 \\
\hline Male & 46.5 & 70,67 & 56.5 & 77,76 \\
\hline Female & 41.5 & 68,82 & 46.5 & 81,73 \\
\hline \multicolumn{5}{|c|}{ SF-36 physical functioning $(0-100)$} \\
\hline Total population & 72.5 & 69,68 & 81.7 & 75,78 \\
\hline Acute & 72.5 & 68,63 & 81.7 & 75,74 \\
\hline Chronic & 72.5 & 70,71 & 82.5 & 75,80 \\
\hline Surgery & 67.5 & 73,80 & 82.5 & 73,84 \\
\hline
\end{tabular}

Table 3 continued

\begin{tabular}{llllll}
\hline & 3 months & & & 12 months & \\
\cline { 2 - 3 } \cline { 6 - 7 } & $\begin{array}{l}\text { Cut-off } \\
\text { value }\end{array}$ & $\begin{array}{l}\text { Sens, } \\
\text { spec }\end{array}$ & & $\begin{array}{l}\text { Cut-off } \\
\text { value }\end{array}$ & $\begin{array}{l}\text { Sens, } \\
\text { spec }\end{array}$ \\
\hline No surgery & 72.5 & 72,66 & 81.7 & 77,76 \\
Male & 77.5 & 66,68 & 81.7 & 85,74 \\
Female & 67.5 & 78,65 & 77.5 & 75,78 \\
\hline
\end{tabular}

Cut-off values are presented at 3- and 12-month follow-up for the total population and the subgroups: sciatica duration $<3$ months at inclusion (acute), sciatica duration $\geq 3$ months at inclusion (chronic), surgery registered at 3- respectively, 12-month follow-up, no surgery, male and female

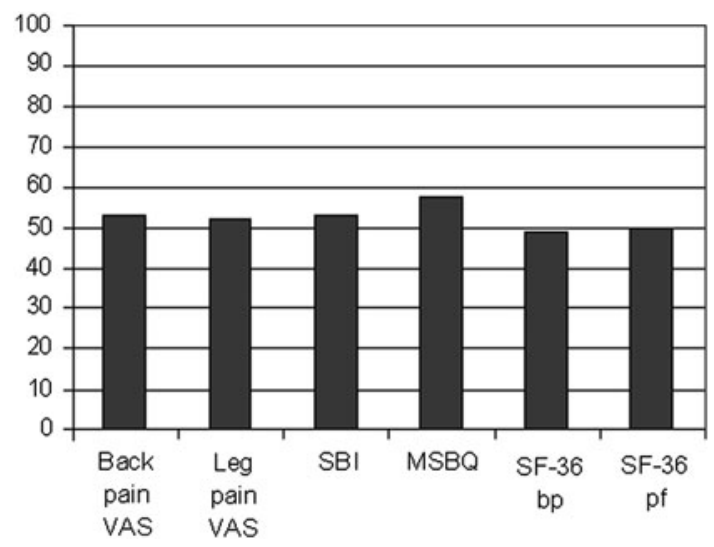

Fig. 2 Per cent of patients achieving success according to calculated cut-off values for back and leg pain VAS, Sciatica Bothersomeness Index (SBI), Maine-Seattle Back Questionnaire (MSBQ), and SF-36 bodily pain (bp) and physical functioning (pf)

follow-up were similar, which is in agreement with the Cochrane Review and other observational studies [1, 6, 23].

The global change scores correspond to the results of the MLSS study [1]. This shows that many patients still experience pain and disability after 1 year.

Definition of recovery in terms of a cut-off point enables comparison of results between studies. To our knowledge, two previous studies proposed a defined score for evaluating recovery from sciatica. Both studies used composite scores and presented strict definitions. One study defined recovery from sciatica as ODI $\leq 20+$ VAS pain $\leq 15+$ muscle strength 5/5 [3], and another used the definition absence of sciatic leg pain $0 / 10+$ RMDQ $\leq 3$ [9]. Low back pain recovery has in other studies been defined using cut-off points, but there is lack of consistency among the measures [10].

There are limitations to the study. Number and characteristics of eligible patients who did not enter the study were not registered. Clinical examination was carried out by different physiotherapists and physicians; this might 
give an assessment error. The ODI and the RMDQ were not used for comparison with the sciatica specific questionnaires.

In conclusion, using the cut-off scores which best discriminated the patients with and without success at 1 year, the success rates varied from 49 to $58 \%$ depending on the measure used.

Acknowledgments Supported by a grant from the South-Eastern Norway Regional Health Authority. We thank Eli Molde Hagen, Knut Morten Huneide, Anett Bjørnødegård and Bjarte Justnæs for their help with the data collection and Leiv Sandvik for statistical advice.

\section{Conflict of interest None.}

Open Access This article is distributed under the terms of the Creative Commons Attribution Noncommercial License which permits any noncommercial use, distribution, and reproduction in any medium, provided the original author(s) and source are credited.

\section{References}

1. Atlas SJ, Deyo RA, Keller RB, Chapin AM, Patrick DL, Long JM, Singer DE (1996) The Maine lumbar spine study, part II. 1-year outcomes of surgical and nonsurgical management of sciatica. Spine 21:1777-1786

2. Atlas SJ, Deyo RA, van den Ancker M, Singer DE, Keller RB, Patrick DL (2003) The Maine-Seattle back questionnaire: a 12-item disability questionnaire for evaluating patients with lumbar sciatica or stenosis: results of a derivation and validation cohort analysis. Spine 28:1869-1876

3. Balague F, Nordin M, Sheikhzadeh A, Echegoyen AC, Brisby H, Hoogewoud HM, Fredman P, Skovron ML (1999) Recovery of severe sciatica. Spine 24:2516-2524

4. Bombardier C (2000) Outcome assessments in the evaluation of treatment of spinal disorders: summary and general recommendations. Spine 25:3100-3103

5. Copay AG, Glassman SD, Subach BR, Berven S, Schuler TC, Carreon LY (2008) Minimum clinically important difference in lumbar spine surgery patients: a choice of methods using the Oswestry Disability Index, Medical Outcomes Study questionnaire Short Form 36, and pain scales. Spine J 8:968-974

6. Gibson JN, Waddell G (2007) Surgical interventions for lumbar disc prolapse: updated cochrane review. Spine 32:1735-1747

7. Grovle L, Haugen AJ, Keller A, Natvig B, Brox JI, Grotle M (2008) Reliability, validity, and responsiveness of the Norwegian versions of the Maine-Seattle back questionnaire and the Sciatica Bothersomeness and frequency indices. Spine 33:2347-2353

8. Hoogland T, Schubert M, Miklitz B, Ramirez A (2006) Transforaminal posterolateral endoscopic discectomy with or without the combination of a low-dose chymopapain: a prospective randomized study in 280 consecutive cases. Spine 31:E890-E897

9. Jensen TS, Albert HB, Sorensen JS, Manniche C, Leboeuf-Yde C (2007) Magnetic resonance imaging findings as predictors of clinical outcome in patients with sciatica receiving active conservative treatment. J Manipulative Physiol Ther 30:98-108
10. Kamper SJ, Stanton TR, Williams CM, Maher CG, Hush JM et al (2011) How is recovery from low back pain measured? A systematic review of the literature. Eur Spine J 20:9-18

11. Koes BW, van Tulder MW, Peul WC (2007) Diagnosis and treatment of sciatica. BMJ 334:1313-1317

12. Luijsterburg PAJ, Verhagen AP, Ostelo RWJG, van den Hoogen HJMM, Peul WC, Avezaat CJJ, Koes BW (2008) Physical therapy plus general practitioners' care versus general practitioners' care alone for sciatica: a randomised clinical trial with a 12-month follow-up. Eur Spine J 17:509-517

13. Mannion AF, Porchet F, Kleinstuck FS, Lattig F, Jeszenszky D, Bartanusz V, Dvorak J, Grob D (2009) The quality of spine surgery from the patient's perspective: part 2. Minimal clinically important difference for improvement and deterioration as measured with the Core Outcome Measures Index. Eur Spine J 18(Suppl 3):374-379

14. Nykvist F, Hurme M, Alaranta H, Einola S (1989) A prospective 5-year follow-up study of 276 patients hospitalized because of suspected lumbar disc herniation. Int Disabil Stud 11:61-67

15. Osterman H, Seitsalo S, Karppinen J, Malmivaara A (2006) Effectiveness of microdiscectomy for lumbar disc herniation: a randomized controlled trial with 2 years of follow-up. Spine (Phila Pa 1976) 31:2409-2414

16. Patrick DL, Deyo RA, Atlas SJ, Singer DE, Chapin A, Keller RB (1995) Assessing health-related quality of life in patients with sciatica. Spine 20:1899-1908; discussion 1909

17. Peul WC, van Houwelingen HC, van den Hout WB, Brand R, Eekhof JA, Tans JT, Thomeer RT, Koes BW, Leiden-The Hague Spine Intervention Prognostic Study Group et al (2007) Surgery versus prolonged conservative treatment for sciatica. N Engl J Med 356:2245-2256

18. Saal JA, Saal JS (1989) Nonoperative treatment of herniated lumbar intervertebral disc with radiculopathy. An outcome study. Spine 14:431-437

19. Terwee CB, Bot SD, de Boer MR, van der Windt DA, Knol DL, Dekker J, Bouter LM, de Vet HC (2007) Quality criteria were proposed for measurement properties of health status questionnaires. J Clin Epidemiol 60:34-42

20. Thomas KC, Fisher CG, Boyd M, Bishop P, Wing P, Dvorak MF (2007) Outcome evaluation of surgical and nonsurgical management of lumbar disc protrusion causing radiculopathy. Spine 32:1414-1422

21. Ware JE Jr, Sherbourne CD (1992) The MOS 36-item short-form health survey (SF-36). I. Conceptual framework and item selection. Med Care 30:473-483

22. Weber H, Holme I, Amlie E (1993) The natural course of acute sciatica with nerve root symptoms in a double-blind placebocontrolled trial evaluating the effect of piroxicam. Spine 18:1433-1438

23. Weinstein JN, Lurie JD, Tosteson TD, Skinner JS, Hanscom B, Tosteson AN, Herkowitz H, Fischgrund J, Cammisa FP, Albert T, Deyo RA (2006) Surgical vs nonoperative treatment for lumbar disk herniation: the Spine Patient Outcomes Research Trial (SPORT) observational cohort. JAMA 296:2451-2459

24. Weinstein JN, Tosteson TD, Lurie JD, Tosteson AN, Hanscom B, Skinner JS, Abdu WA, Hilibrand AS, Boden SD, Deyo RA (2006) Surgical vs nonoperative treatment for lumbar disk herniation: the Spine Patient Outcomes Research Trial (SPORT): a randomized trial. JAMA 296:2441-2450 